\title{
Opinion controversy to chromium picolinate therapy's safety and efficacy: ignoring 'anecdotes' of case reports or recognising individual risks and new guidelines urgency to introduce innovation by predictive diagnostics?
}

\author{
Olga Golubnitschaja* and Kristina Yeghiazaryan
}

\begin{abstract}
Due to the important physiologic function of trivalent chromium in glucose/insulin homeostasis, some commercial organisations promote $\mathrm{Cr}^{3+}$ supplements in maintaining proper carbohydrate and lipid metabolism; regulation of reducing carbohydrate carvings and appetite; prevention of insulin resistance and glucose intolerance; regulation of body composition, including reducing fat mass and increasing lean body mass; optimal body building for athletes; losing weight; treatment of atypical depression as an antidepressant; and prevention of obesity and type 2 diabetes mellitus. On one hand, case reports are commented as 'nonevidence-based anecdotes'. On the other hand, a number of independent studies warn against adverse health outcomes assigned to chromium picolinate (CrPic) dietary application. This review analyses opinion controversies, demonstrates highly individual reactions towards CrPic dietary supplements and highlights risks when the dietary supplements are used freely as therapeutic agents, without application of advanced diagnostic tools to predict individual outcomes.
\end{abstract}

Keywords: Patient records, Individual profiles, Subcellular imaging patterns, Therapy response, Pre/diabetes care, New guidelines, Predictive preventive personalised medicine, Dietary supplements, Healthcare, Integrative medicine

\section{Review}

\section{Changing long-held beliefs is never easy}

As a consequence of the accumulating clinical data and knowledge about the epidemiology and pathological mechanisms of the most frequent causes of morbidity and mortality, we are currently reconsidering our view of the origins and progression of cardiovascular, oncologic and neurodegenerative diseases. The majority of these pathologies are of chronic nature: they progress from precursor lesions over one or even several decades of life; therefore, it is often too late for effective therapeutic intervention. An excellent example is the epidemic scale of type 2 diabetes mellitus witnessed in the European Union. In most industrialised countries and countries with large populations, the permanently growing cohort of diabetics

\footnotetext{
* Correspondence: Olga.Golubnitschaja@ukb.uni-bonn.de

Department of Radiology, Rheinische Friedrich-Wilhelms-University of Bonn, Sigmund-Freud-Str. 25, Bonn 53105, Germany
}

creates a serious healthcare problem and a dramatic health economic burden. The estimate for diabetes prevalence in the years 2025-2030 is half a billion patients worldwide (see Figure 1).

Moreover, the contemporary onset of the dominant type 2 diabetes was already observed in subpopulations of teenagers [3]. Severe complications secondary to early onset of diabetes mellitus, such as retinopathy, nephropathy, silent ischaemia, dementia and cancer (Figure 2), soon may lead to collapsing healthcare systems [4].

Optimistic versus pessimistic prognosis in future developments of the healthcare sector depends much on diagnostic, preventive and treatment approaches which diabetes care will preferably adopt in the near future. Without innovation in healthcare, diabetes-related complications may cause such a dramatic level of burden that any performance of personalised medicine will not be feasible from an economical point of view. In contrast, effective 


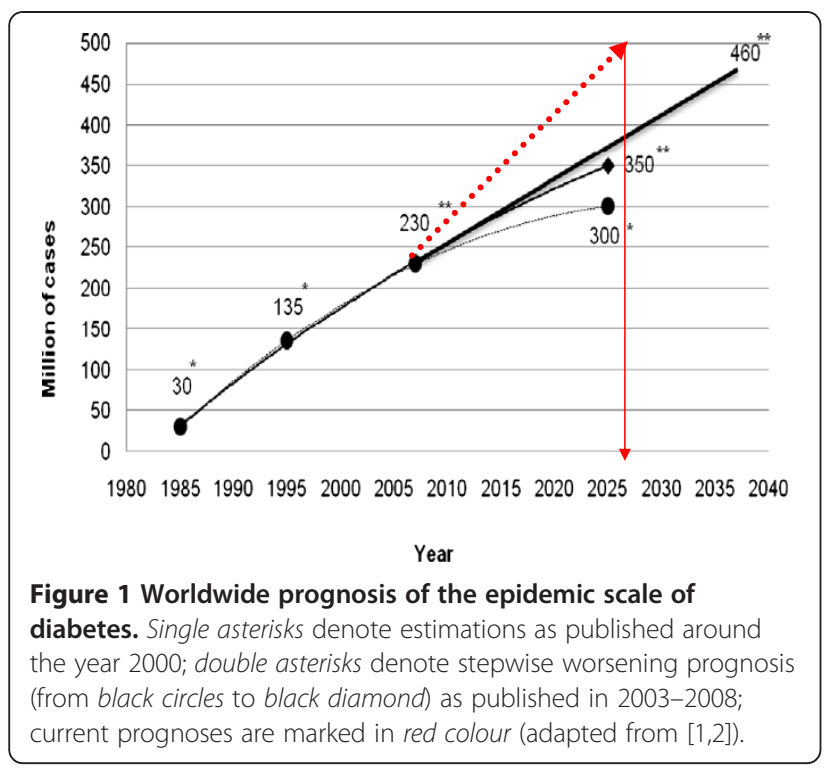

utilisation of advanced early/predictive diagnostics and targeted prevention could enable rapidly ageing populations in Europe and elsewhere to be economically effective for the society. Therefore, it is timely to consider the integrative medical approaches to advance pre/diabetes care utilising the innovation by predictive diagnostics as the basis for concomitant targeted prevention, patient profiling as the basis for individualised treatment algorithms and medical approaches tailored to the patient [5-8].

The message is that new guidelines should create a robust juristic and economic platform for advanced medical services utilising the cost-effective models of risk assessment followed by tailored treatments focussed on the precursor stages of chronic disease [9].

\section{Potential role of biologically active chromium in diabetes prevention}

Chromium is an essential trace element in human physiology. The physiologic value of chromium compounds depends on the oxidative states of chromium ions that vary from bivalent to hexavalent ones. The best investigated forms are trivalent and hexavalent chromium compounds. The latter is frequently used in a variety of industrial technologies. Chronic exposure to it has been shown to be responsible for a spectrum of severe health problems affecting the skin and inner organs [10]. Investigations of its carcinogenic effects are in progress at molecular and cellular levels $[11,12]$. In contrast, trivalent chromium is considered physiologically safe and is an essential trace metal functionally involved in several metabolic pathways in human beings as published elsewhere. The recommended daily allowance of trivalent chromium corresponds to the range of 50-200 $\mu \mathrm{g}$ [13]. Dietary deficiency of chromium leads to disturbances in carbohydrate metabolisms; increases risk of glucose intolerance, insulin resistance, hyperglycaemia and predisposes to obesity and type 2 diabetes mellitus $[14,15]$.

\section{Controversial benefits by $\mathrm{Cr}^{3+}$ nutrient supplement in foods}

Biologically valuable forms of chromium are compounds of trivalent chromium bound to low molecular weight organic complexes such as oligopeptides. This recognition led to the development of a commercial branch with $\mathrm{Cr}^{3+}$ nutrient supplements which suppose to promote or even improve health status.

What are the currently available 'pro' versus 'contra' arguments to approve/disprove potential benefits of $\mathrm{Cr}^{3+}$ nutrient supplement?

Chromium is an essential metal, but only traces of trivalent chromium are utilised in the human body for glucose conversion by insulin-driven reactions in carbohydrate metabolic pathways. Furthermore, naturally available food sources used in well-balanced diets are capable to cover the requirement of trivalent chromium completely: fruits, vegetables, meat, fish, grains, brewer's yeast, etc. [16]. Cr deficiency cases are extremely rare, and evidence-based biochemical justification for artificial source needed

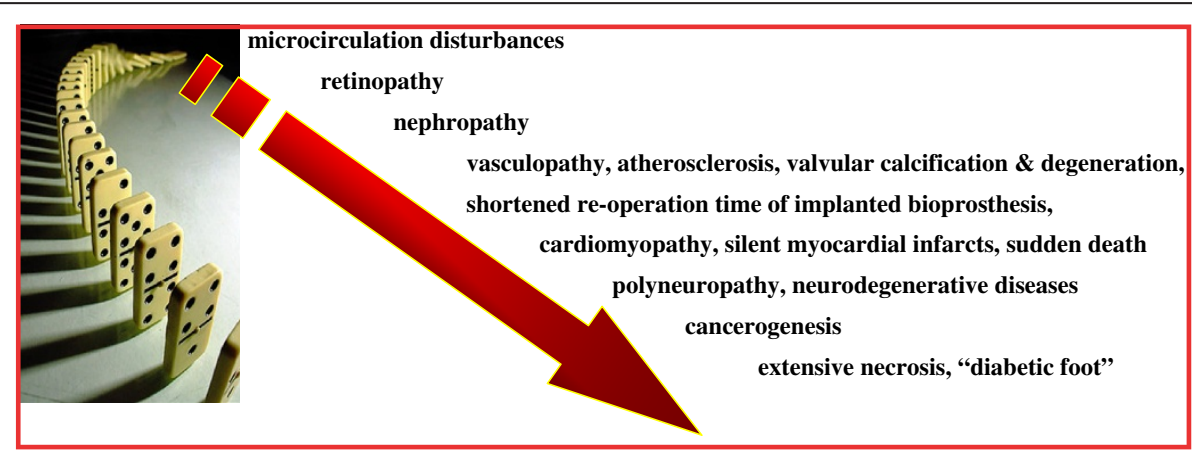

Figure 2 Severe complications developed secondary to diabetes: from 'upstream' (up) to 'downstream' (bottom) in the cascade of pathologic processes (adapted from [4]). 
additionally to standard foods has not been provided in the literature. Nevertheless, due to the important physiologic function of trivalent chromium in maintaining proper carbohydrate and lipid metabolism and glucose/ insulin homeostasis, some commercial organisations promote $\mathrm{Cr}^{3+}$ nutrient supplements in

- regulation of reducing carbohydrate carvings and appetite

- prevention of insulin resistance and glucose intolerance

- regulation of body composition, including reducing fat mass and increasing lean body mass

- optimal body building for athletes

- losing weight

- treatment of atypical depression as an antidepressant

- prevention of obesity and type 2 diabetes mellitus.

The widely spread chemical compound used as a trivalent chromium nutrient supplement is chromium picolinate (CrPic). CrPic has become a very popular nutritional supplement for treating type 2 diabetic, obese and diabetespredisposed individuals [17]. However, over a decade of human studies with $\mathrm{CrPic}$ indicate that the supplement has not demonstrated effects on the body composition of healthy individuals, even when taken in combination with an exercise training programme [18]. Also, a potential weight loss by CrPic therapy has not been confirmed [19].

After the evidence-based search into the issue, the US Food and Drug Administration concluded that the 'relationship between $\mathrm{CrPic}$ intake and insulin resistance is highly uncertain' [20]. Furthermore, some later studies have concluded that ' $\mathrm{CrPic}$ does not improve key features of metabolic syndrome in obese nondiabetic adults' [21]. Nevertheless, it is reported that CrPic generates sales for more than US\$100 million annually [22]. The $\mathrm{CrPic}$ supplements are freely available in numerous forms including chewing gums, pills, sports drinks and nutrition bars [23]. CrPic is commonly supplied in the range of $200-500 \mu \mathrm{g}$ as a daily dose [13]. A big advantage of $\mathrm{CrPic}$ is its high bioavailability due to increased absorbing capacity in human tissues compared with dietary chromium [24]. However, the mechanism of action of $\mathrm{CrPic}$ at molecular level is not completely understood. In 1999, Speetjens et al. reported that CrPic cleaves DNA molecules by a radical mechanism: in the presence of oxygen from air and biologically available reductants, $\mathrm{CrPic}$ generates hydroxyl radicals damaging DNA molecules [25]. Further, organisms exposed to CrPic demonstrate the tendency to accumulate intracellular $\mathrm{Cr}^{3+}$ ions that may lead to long-term genotoxic effects by formation of covalent bonds to DNA [26]. Taken together, cytotoxic, genotoxic and mutagenic effects as well as activity damaging to the mitochondria and induction of apoptosis have been reported for CrPic-using mammalian cell cultures, Drosophila and animal models [27-30]. Potential toxicity of $\mathrm{CrPic}$ has raised concerns about the safety of CrPic-related nutrient supplements.

\section{Animal experiments to model treatment effects of CrPic on human beings}

To simulate treatment effects of CrPic, a spectrum of models has been used. To simulate type 2 diabetes mellitus (DM), a well-acknowledged animal model of $\mathrm{db} / \mathrm{db}$ mice was utilised in a recent project [31]. The experimental design is summarised in Figure 3.

\section{Subcellular imaging insights into CrPic therapy Quantitative subcellular imaging by 'comet assay' analysis}

The single-cell gel electrophoresis assay is a simple and effective method for evaluating DNA damage in cells. It is based on the ability of denatured, cleaved DNA fragments to migrate out of the cell under the influence of an electric field, whereas undamaged DNA remains within the confines of the nucleoid and migrates slower. The assessment of DNA damage is done via the evaluation of the DNA 'comet' tail shape and migration pattern. The cells are immobilised in a bed of low-melting point agarose, on a Trevigen CometSlide ${ }^{\mathrm{TM}}$ (Gaithersburg, MD, USA). After cell lysis, samples are treated with alkali to unwind and denature the DNA and hydrolyse sites of damage. After performing electrophoresis, staining with a fluorescent DNA-intercalating dye $\left(\mathrm{SYBR}^{\circledR}\right.$ Green I; Trevigen Inc., Gaithersburg, MD, USA) is done, and the sample is visualised by epifluorescence microscopy. The alkaline electrophoresis is very sensitive and allows for the detection of small amounts of damage.

In our experiments, DNA damage was designated to four classes based on the visual aspect considering the extent of DNA migration as published earlier [32]. Comets with a bright head and almost no tail were classified as class I, indicating minimal DNA damage, whereas comets with no visible head and a long diffuse tail were classified as class IV, revealing complete DNA fragmentation. Comets with intermediate characteristics were assigned to classes II and III based on the ratio $R=T / r$, in which $T$ represents the comet's tail length and $r$ is the radius of the comet's head. The characteristic value of $R$ for class $I$ is 1 and that for class IV is $\infty$ $(r=0)$. Comets with $R$ values ranging between $1<R>3$ were designated as class II. The comet classification is demonstrated in Figure 4A. Figure 4B demonstrates comet patterns typical for experimental group 1 (left) with the lowest level of comets of class IV (apoptosis) and experimental groups 5-7 (right) with the highest level of apoptosis. 


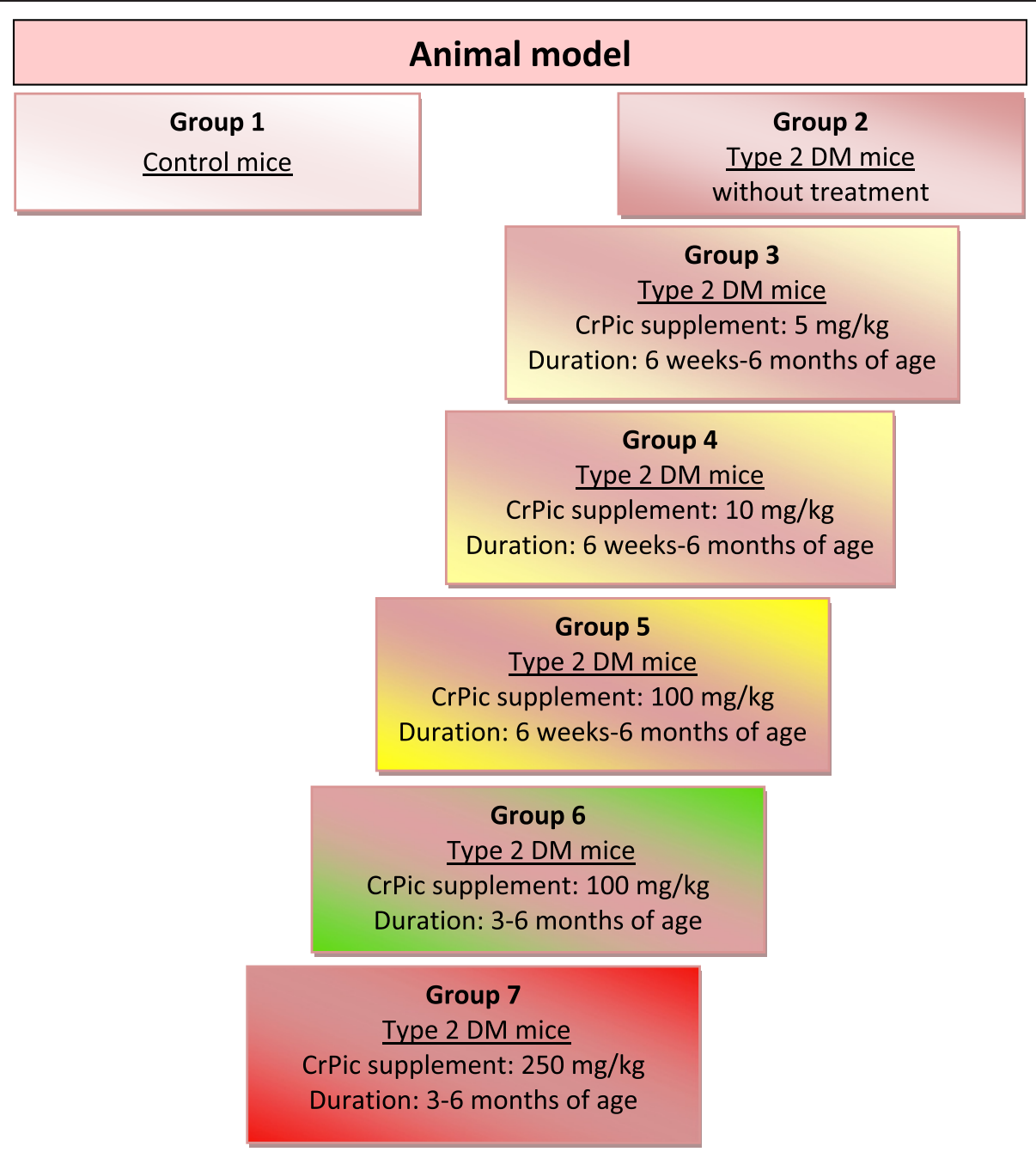

Figure 3 Experimental design to model CrPic treatment effects. Animals were arranged in eight groups. Group 1 represented the healthy control. Group 2 was the model mice for type 2 DM. Groups 3-7 were diabetes model mice treated under individual algorithms: 5 mg/kg CrPic from 6 weeks to 6 months of age (group 3), 10 mg/kg CrPic from 6 weeks to 6 months of age (group 4), 100 mg/kg CrPic from 6 weeks to 6 months of age (group 5), $100 \mathrm{mg} / \mathrm{kg}$ CrPic from 3 to 6 months of age (group 6), and $250 \mathrm{mg} / \mathrm{kg}$ CrPic from 3 to 6 months of age (group 7). Kidney tissue samples were collected and stored at $-80^{\circ} \mathrm{C}$ till the analysis described in the below section was performed.

\section{Statistical analysis reveals increased heterogeneity of} individual reactions towards the highest doses of $\mathrm{CrPic}$

Statistical analysis of comets in classes I (intact DNA) and IV (apoptosis) is demonstrated in Figure 5A, B, respectively. The red frame marks the experimental groups with the highest rates of statistical deviations towards the mean value. The highest heterogeneity is obvious for groups 5, 6 and 7, i.e. the experimental groups with the highest doses of $\mathrm{CrPic}$ applied as treatment.

DNA damage in untreated diabetic group is significantly higher compared to healthy control group

Quantitative subcellular imaging by comet assay analysis revealed significantly higher DNA damage in the untreated diabetic group compared to healthy controls (see
Figure 6) that is well in agreement with data published and reviewed for diabetic patients $[4,8]$.

\section{Individuality within the untreated diabetic group}

Subcellular imaging generally revealed group-specific patterns when diabetic animals were compared with controls, although higher heterogeneity was demonstrated within the untreated diabetic group: in some animals, intact DNA (class I comets) was monitored, whereas only comet classes with damaged DNA were monitored for others (see Figure 7). This heterogeneity clearly demonstrates an individualised reaction of organisms towards diabetic condition. This is a very important observation that corresponds well with the clinical picture of diabetes [8]. Hence, it is conclusive that the 
A.

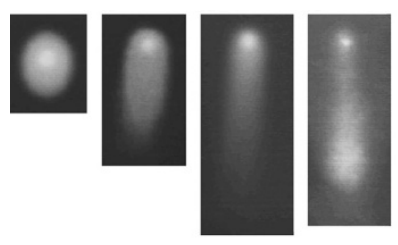

B.
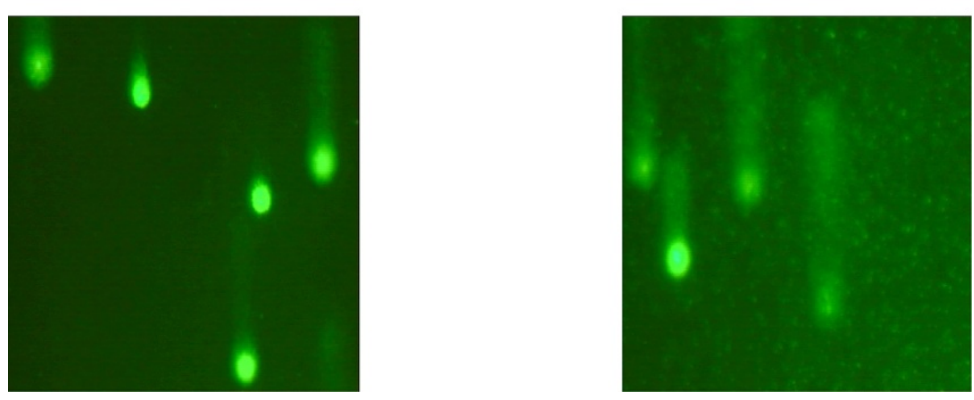

Figure 4 Microscopic imaging. (A) Comet classes I, II, III and IV (from left to right); (B) comet pattern typical for experimental group 1 (left, low apoptosis rates) and experimental groups 5-7 (right, high apoptosis rates).

animal model used is suitable for issue-related studies to simulate the medical condition of diabetes and investigate individualised therapeutic effects.

Highly individual reaction of diabetic animals towards CrPic dietary supplements

Despite group-specific patterns, the subcellular imaging by the comet assay indicated that each animal within a group responded individually to the identical dosage of CrPic administered and the treatment duration. Within the diabetic groups, experimental animals demonstrated highly individual comet patterns with respect to single dosages and treatment algorithms. This observation is important in regard of the highly individual response to the treatment algorithms applied. The paper concludes that there are individual reactions of diabetic animals towards doses and duration of CrPic treatment. This observation
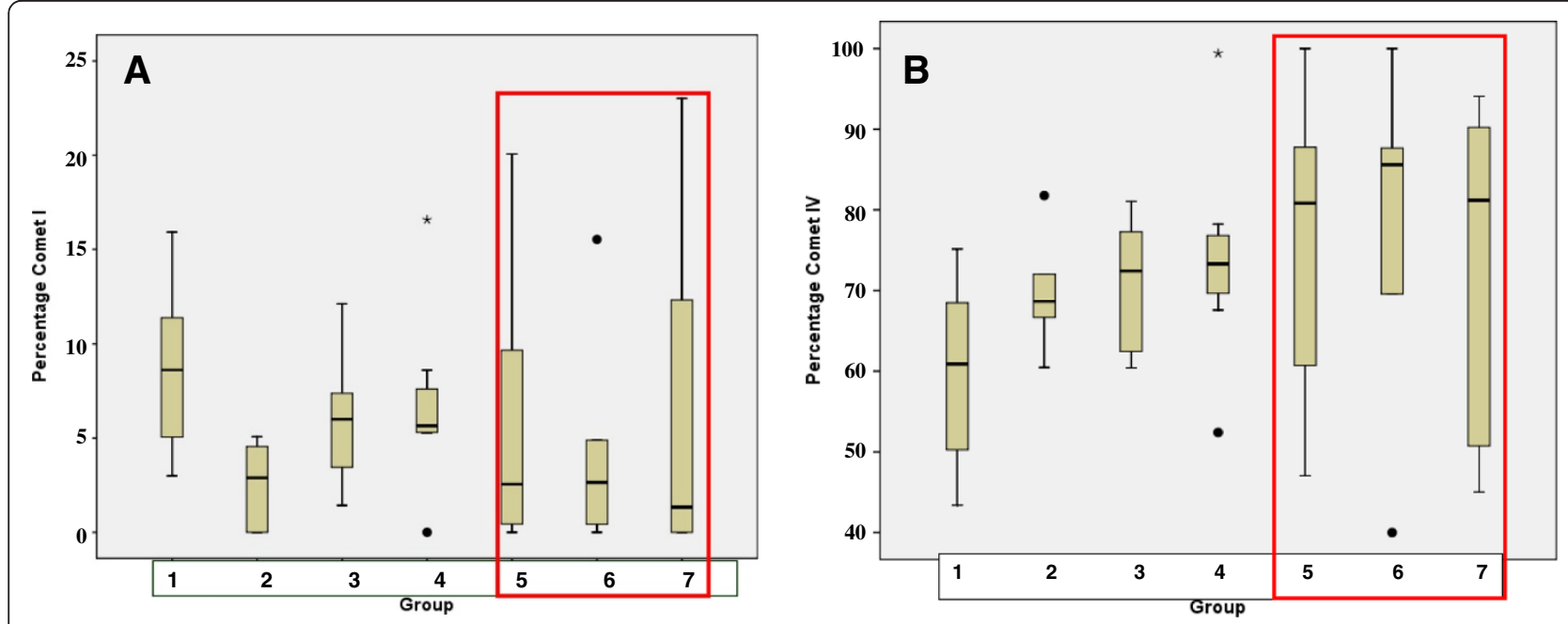

Figure 5 Statistical analyses for the comet types (A) I and (B) IV (see 'comet classification' in Figure 4A) in groups of comparison as described in Figure 3 ('experimental design'). Analyses were carried out using SPSS 17.0 software (SPSS, Chicago, IL, USA) by the application of univariable variance analysis with Bonferroni. The red box marks the groups with the highest deviation towards the mean value, i.e. the greatest heterogeneity within corresponding groups. The individual values which go overboard by statistical calculations are marked with black circles (for the standard deviation in groups 4 and 6) and asterisk (for the mean value in group 4). 


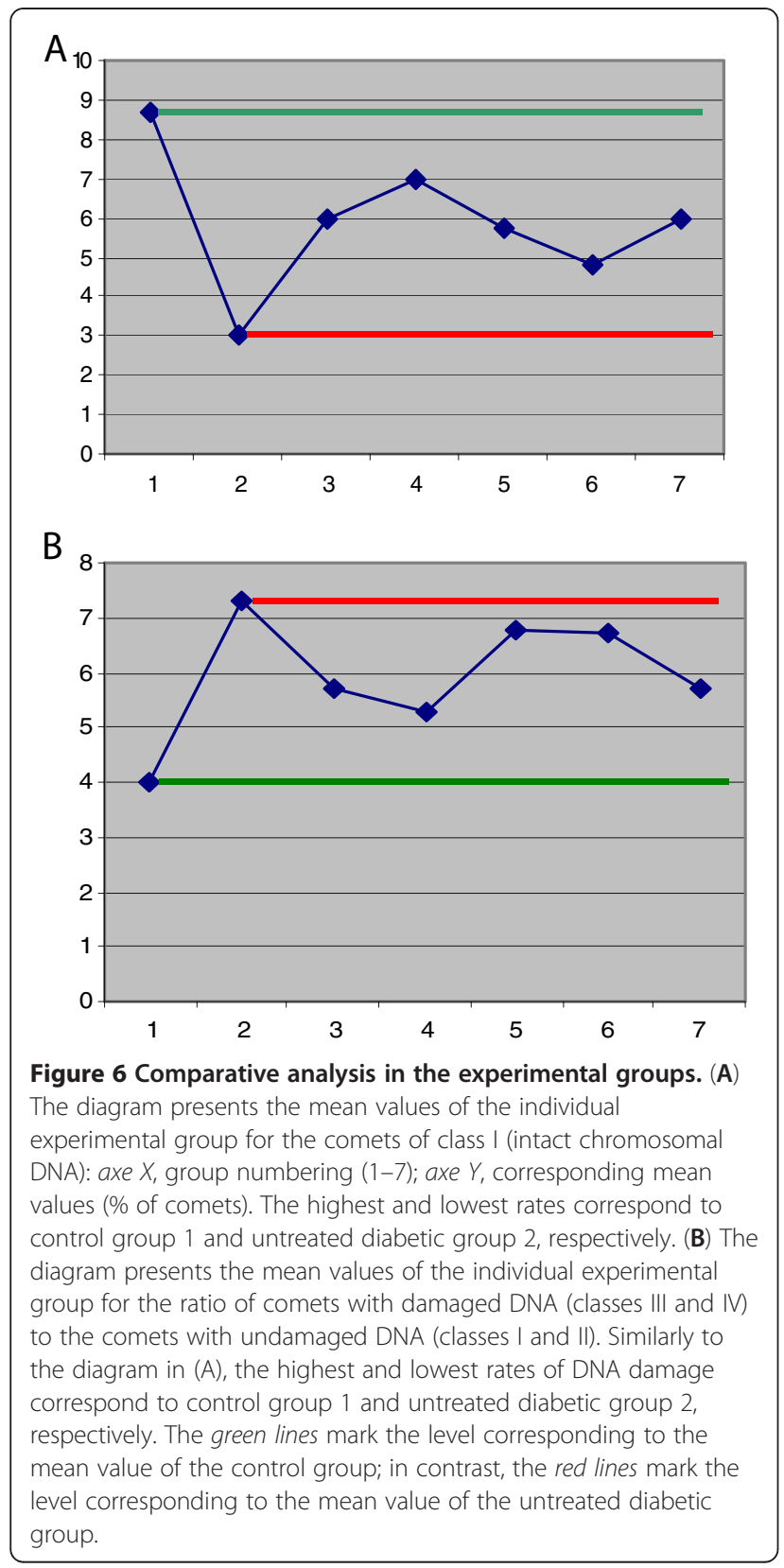

can explain discrepancies found in the literature concerning harmful effects of CrPic therapy [13,24-28].

The authors interpreted that CrPic treatment effects are unpredictable for the patient cohort as a whole, due to highly individual reactions towards therapy. Individuals should be treated personally on the basis of individual results going by predictive diagnostics and therapy monitoring.

\section{Group-pecific comparative quantification of apoptosis under CrPic treatments}

All diabetic groups demonstrate apoptotic rates which are significantly higher compared to the control group (see Figure 8). The highest rates of apoptosis were monitored in the diabetic groups treated with the highest doses of CrPic, namely in the groups 5, 6 and 7 .

\section{Assumed and registered adverse health outcomes by CrPic treatments}

Taken the above observations together, the authors conclude possible risks for individual long-term effects when $\mathrm{CrPic}$ is freely used as a therapeutic nutritional modality agent without application of advanced diagnostic tools to predict individual outcomes.

\section{In experimental models}

In terms of potential treatments of gestational diabetes, there is very little information about the safety of CrPic applied as a dietary supplement in pregnant women. However, experiments performed with CrPic administered to pregnant mice resulted in skeletal birth defects in the developing fetus [33].

Comparative cytotoxic and genotoxic studies of trivalent chromium demonstrated that the compound's safety depends on the ligand bound to the chromium ion [34]. Thereby, CrPic produces significantly more oxidative stress and DNA damage compared, for example, to niacin-bound chromium(III). The implicated toxicity of CrPic may result in renal impairment; severe biochemical, histological and morphological changes in the eye; skin blisters and pustules; anaemia; hemolysis; tissue oedema; liver dysfunction; neuronal cell injury; impaired cognitive, perceptual and motor activity; enhanced production of hydroxyl radicals; chromosomal aberration; depletion of antioxidant enzymes; oxidative stress and DNA damage [23,29,34-38]. Increased apoptotic effects by CrPic were demonstrated by the authors of this study for kidney and for circulating leukocytes elsewhere $[17,39]$. Potential carcinogenic effects are assumed $[40,41]$.

\section{In humans}

A growing body of case reports warns against adverse health outcomes assigned to CrPic dietary application, whereas by others, they are interpreted as 'anecdotal reports' [42]. Hence, case reports have described acute kidney failure, liver damage and anaemia by taking high dosage of $\mathrm{CrPic}$ as a dietary supplement [43,44]. Adverse cutaneous reactions to $\mathrm{CrPic}$ supplements have also been described [45].

Furthermore, there are some concerns that CrPic may affect the levels of neurotransmitters leading to potential risks for patients treated for depression, bipolar disorder and schizophrenia [18]. In a broader sense, CrPic supplements are hormone-related and may influence hormone secretion through their function in the endocrine/ metabolic system [46]. Chromium supplements taken 


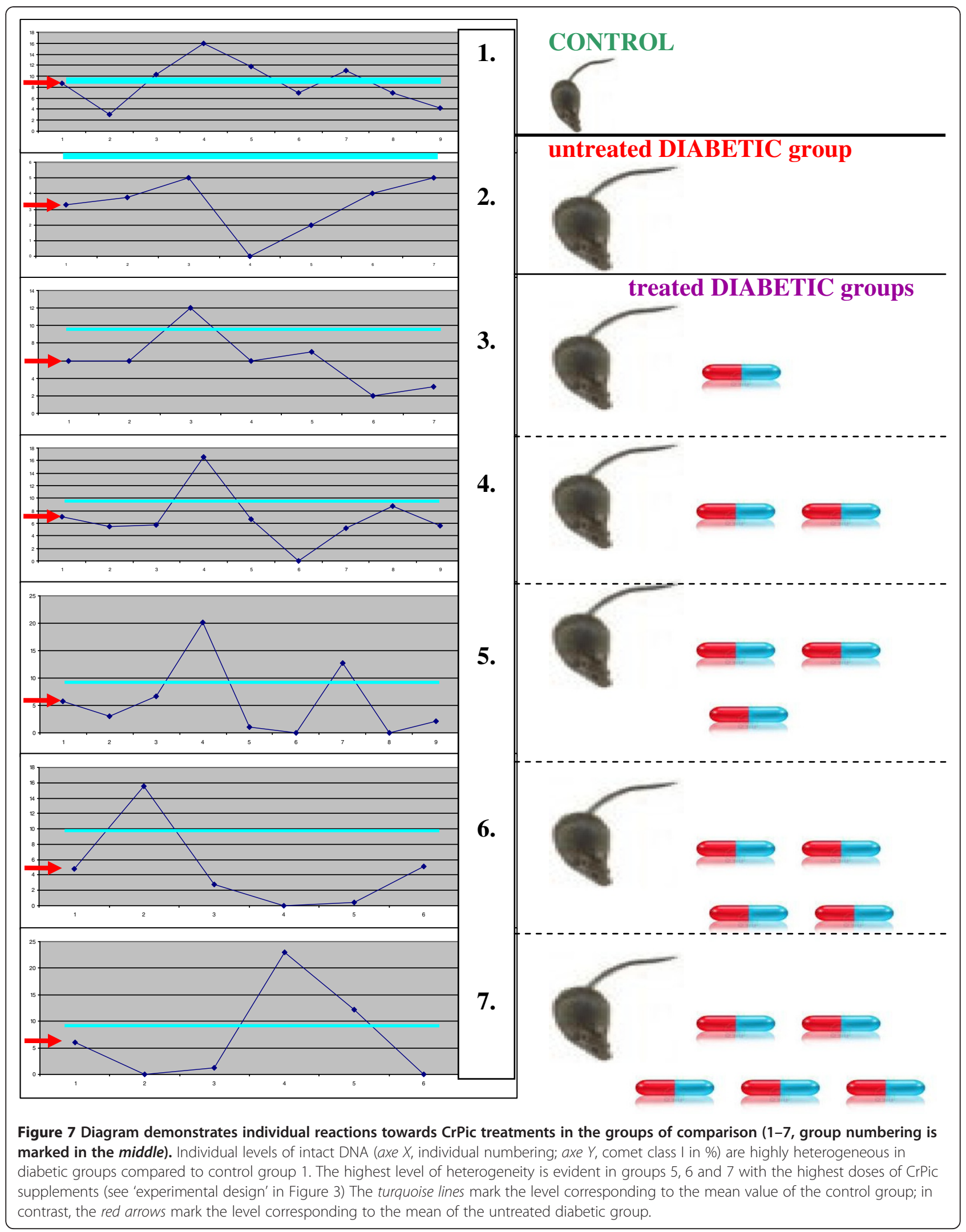




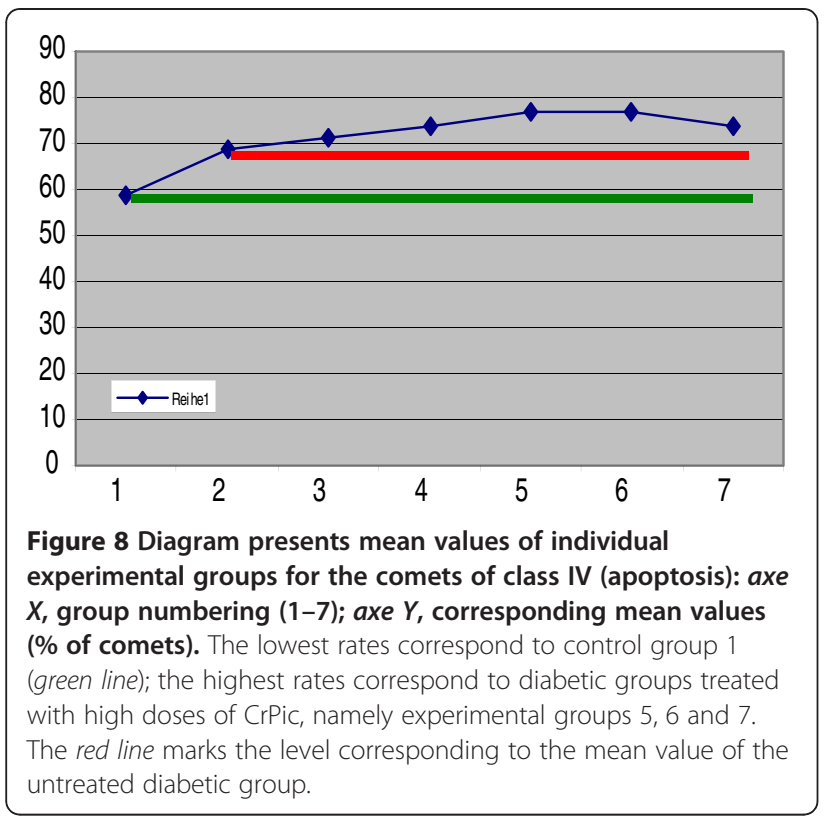

together with medications that block the formation of prostaglandins, such as ibuprofen, indomethacin, naproxen and aspirin, may increase the absorption of chromium in the body followed by unpredictable consequences such as long-term genotoxic effects caused by formation of covalent bonds to DNA molecules [26]. Some additive medication effects may be expected if CrPic therapy is combined with diabetes treatments, causing blood glucose levels to dip too low.

Here, the authors are wishing to stress the point that according to our analysis, the above listed adverse health effects are not expected to happen to everybody. They may occur individually with a severity grade depending on individual predispositions but can be effectively avoided by application of advanced diagnostic tools for the therapy monitoring and to predict individual outcomes. Further, the authors appeal to react effectively towards the case reports demonstrating adverse health outcomes by artificial dietary supplements often regarded as harmless by the public and lay media.

\section{Conclusions and recommendations}

Artificial supplements for diabetes prevention: hype or hope?

Definitely, CrPic therapy is solely one example of several therapy forms which currently are applied 'across-theboard' in diabetes care. The administration of artificial supplements is an attempt to prevent or at least to postpone the onset of type 2 diabetes in the group of risk and with individuals who are unwilling to make prudent changes in their diets and sedentary habits. Should this approach be considered as the hype or the hope? Considering type 2 diabetes as a multifactorial disease, our answer is that the above question is rather of rhetoric nature.

High efficacy of a balanced diet, an individually optimised lifestyle and personalised treatment regiments can hardly be substituted by a limited number of single supplements to cover all the multifactorial risks such as the upward trends of population ageing, environmental risk factors, urbanisation, additive effects of diverse stress factors, incorrectly chosen lifestyle including unfavourable nutritional habits, increasing prevalence of obesity, low physical activity, etc.

Although ageing is the well-acknowledged factor contributing to the disease's development, there are completely new epidemiologic factors characteristic of the twenty-first century that speed up the disease's progression particularly in the youth and in the young adults. Hence, it has been demonstrated that the prognosed DM rate progression will be inversely increasing with age (younger age $=$ higher progression), and the youngest group of 20-39-year-old people will be delivering the highest rates of diabetic progression which will double the diabetes mellitus cohort of this age group by the year 2030 compared to 2010 [47]. This is a completely new situation and a very big challenge for most societies around the globe, requiring special competencies of several groups of professionals as well as innovative approaches in healthcare and health economy.

The population at-risk for diabetes is huge and increasing in a pandemic scale. One of the reasons might be the failed attempt to prevent the disease by the application of artificial supplements and drugs with hardly recognised individual risks. Consequently, a multimodal approach of integrative medicine by predictive diagnostics, targeted prevention and individually created treatment algorithms is highly desirable.

As discussed and reviewed earlier, more individualised treatments are desirable in effective protection against diabetic retinopathy and polyneuropathy, diabetes-related cardiovascular complications and cancer [8]. Further, field-related research is needed to establish simplified non-invasive diagnostic approaches for routine medical practice which would allow for an accurate prediction of individualised therapy risks and outcomes. A promising technological platform has been recently created using the detection of circulating nucleic acids in blood plasma [48] and clinical proteomics of body fluids [49].

Targeted measures require a creation of new guidelines that are essential to regulate (renoprotective) therapy approaches and the application of more individualised therapeutic modalities for advanced diabetes care. These measures should provide a legitimate regulation for well-timed predictive diagnostics, an effective prevention and the creation of individualised treatment algorithms in pre/diabetes [50]. 


\section{Competing interests}

The authors declare that they have no competing interests.

\section{Authors' contributions}

KY participated in the design of the study and coordinated the performance of the experimental part. OG performed the design of the project and its coordination and created the concept of the manuscript. Both authors read and approved the final manuscript

\section{Acknowledgements}

The project has been granted by $\mathrm{NIH}$ ('Is chromium-picolinate renoprotective in diabetes?', National Institutes of Health, study no. 1R21 AT003012-01A1). The authors thank Prof. Dr. M. Mozaffari (Georgia Health Sciences University, USA) for providing tissue samples in the project. For the statistical analysis and assistance in preparation of the original paper [31], the authors thank V. Peeva, M.Sc. and A. Shenoy, M.Sc., University of Bonn, Germany.

Received: 11 July 2012 Accepted: 17 August 2012

Published: 7 October 2012

\section{References}

1. George B, Cebioglu M, Yeghiazaryan K: Inadequate diabetic care: global figures cry for preventive measures and personalized treatment. EPMA $J$ 2010, 1:13-18.

2. Golubnitschaja O: Time for new guidelines in advanced healthcare: the mission of The EPMA Journal to promote an integrative view in predictive, preventive and personalized medicine. EPMA J 2012, 3:5.

3. Golubnitschaja O: Time for new guidelines in advanced diabetes care: paradigm change from delayed interventional approach to predictive, preventive \& personalized medicine. EPMA J 2010, 1:3-12

4. Golubnitschaja O: Diabetes mellitus. In Predictive Diagnostics and Personalized Treatment: Dream or Reality. Edited by Golubnitschaja O. New York: Nova Science Publishers Inc; 2009:147-150.

5. Golubnitschaja O, Jaksche A, Moenkemann H, Yeghiazaryan K, Karl SE, Trog D, Schild HH, Löffler KU: Molecular imaging system for possible prediction of active retinopathy in patients with diabetes mellitus. Amino Acids 2005, 28:229-237.

6. Golubnitschaja O: Advanced technologies for prediction of secondary complications in diabetes mellitus. In Predictive Diagnostics and Personalized Treatment: Dream or Reality. Edited by Golubnitschaja O. New York: Nova Science Publishers Inc; 2009:213-230.

7. Mozaffari M, Abdelsayed R, Schaffer S: Diabetic complications: pathogenic mechanisms and prognostic indicators. In Predictive Diagnostics and Personalized Treatment: Dream or Reality. Edited by Golubnitschaja O. New York: Nova Science Publishers Inc; 2009:157-182.

8. Golubnitschaja O: Advanced diabetes care: three levels of prediction, prevention \& personalized treatment. Curr Diabetes Rev 2010, 6:42-51.

9. Golubnitschaja O, Swanton C, Danesi R, Costigliola V: Promoting predictive, preventive and personalised medicine: European event of global importance. EPMA J 2011, 2:131-136.

10. van Heerden PV, Jenkins IR, Woods WP, Rossi E, Cameron PD: Death by tanning-a case of fatal basic chromium sulphate poisoning. Intensive Care Med 1994, 20:145-147.

11. Fan $Y$, Ovesen $J L$, Puga A: Long-term exposure to hexavalent chromium inhibits expression of tumor suppressor genes in cultured cells and in mice. J Trace Elem Med Biol 2012, 26:188-191.

12. Urbano AM, Ferreira LMR, Alpoim MC: Molecular and cellular mechanisms of hexavalent chromium-induced lung cancer: an updated perspective. Curr Drug Metab 2012, 13:284-305.

13. Rhodes MC, Hébert CD, Herbert RA, Morinello EJ, Roycroft JH, Travlos GS, Abdo KM: Absence of toxic effects in F344/N rats and B6C3F1 mice following subchronic administration of chromium picolinate monohydrate. Food Chem Toxicol 2005, 43:21-29.

14. Jeejeebhoy KN, Chu RC, Marliss EB, Greenberg GR, Bruce-Robertson A: Chromium deficiency, glucose intolerance, and neuropathy reversed by chromium supplementation, in a patient receiving long-term total parenteral nutrition. Am J Clin Nutr 1977, 30:531-538.

15. Brown RO, Forloines-Lynn S, Cross RE, Heizer WD: Chromium deficiency after long-term total parenteral nutrition. Dig Dis Sci 1986, 31:661-664.

16. Nielsen F: Chromium. In Modern Nutrition in Health and Disease. Edited by Shils M, Olson J, Shike M. Philadelphia: Lea \& Febiger; 1994:15-30.
17. Jana M, Rajaram A, Rajaram R: Chromium picolinate induced apoptosis of lymphocytes and the signaling mechanisms thereof. Toxicol App/ Pharmacol 2009, 237:331-344.

18. Vincent JB: The potential value and toxicity of chromium picolinate as a nutritional supplement, weight loss agent and muscle development agent. Sports Med 2003, 33:213-230.

19. Yazaki Y, Faridi Z, Ma Y, Ali A, Northrup V, Njike W, Liberti L, Katz DL: A pilot study of chromium picolinate for weight loss. J Altern Complement Med 2010, 16:291-299.

20. Trumbo PR, Ellwood KC: Chromium picolinate intake and risk of type 2 diabetes: an evidence-based review by the United States Food and Drug Administration. Nutr Rev 2006, 64:357-363.

21. labal N, Cardillo S, Volger S, Bloedon LT, Anderson RA, Boston R, Szapary PO: Chromium picolinate does not improve key features of metabolic syndrome in obese nondiabetic adults. Metab Syndr Relat Disord 2009, 7:143-150.

22. Vincent JB: Elucidating a biological role for chromium at a molecular level. Acc Chem Res 2000, 33:503-510.

23. Andersson MA, Petersson Grawé KV, Karlsson OM, Abramsson-Zetterberg $L A G$, Hellman BE: Evaluation of the potential genotoxicity of chromium picolinate in mammalian cells in vivo and in vitro. Food Chem Toxicol 2007, 45:1097-1106.

24. Bailey MM, Sturdivant J, Jernigan PL, Townsend MB, Bushman J, Ankareddi I, Rasco JF, Hood RD, Vincent JB: Comparison of the potential for developmental toxicity of prenatal exposure to two dietary chromium supplements, chromium picolinate and $[\mathrm{Cr} 3 \mathrm{O}(\mathrm{O} 2 \mathrm{CCH} 2 \mathrm{CH} 3)(6(\mathrm{H} 2 \mathrm{O}) 3]+$, in mice. Birth Defects Res B Dev Reprod Toxicol 2008, 83:27-31.

25. Speetjens JK, Collins RA, Vincent JB, Woski SA: The nutritional supplement chromium(III) tris(picolinate) cleaves DNA. Chem Res Toxicol 1999, 12:483-487.

26. Kareus SA, Kelley C, Walton HS, Sinclair PR: Release of $\mathrm{Cr}$ (III) from $\mathrm{Cr}$ (III) picolinate upon metabolic activation. J Hazard Mater 2001, 84:163-174

27. Manygoats KR, Yazzie M, Stearns DM: Ultrastructural damage in chromium picolinate-treated cells: a TEM study. Transmission electron microscopy. J Biol Inorg Chem 2002, 7:791-798.

28. Stearns DM, Silveira SM, Wolf KK, Luke AM: Chromium(III) tris(picolinate) is mutagenic at the hypoxanthine (guanine) phosphoribosyltransferase locus in Chinese hamster ovary cells. Mutat Res 2002, 513:135-142.

29. Hepburn DDD, Xiao J, Bindom S, Vincent JB, O'Donnell J: Nutritional supplement chromium picolinate causes sterility and lethal mutations in Drosophila melanogaster. Proc Natl Acad Sci USA 2003, 100:3766-3771.

30. Stallings DM, Hepburn DDD, Hannah M, Vincent JB, O'Donnell J: Nutritional supplement chromium picolinate generates chromosomal aberrations and impedes progeny development in Drosophila melanogaster. Mutat Res 2006, 610:101-113.

31. Yeghiazaryan K, Peeva V, Shenoy A, Schild HH, Golubnitschaja O: Chromium-picolinate therapy in diabetes care: molecular and subcellular profiling revealed a necessity for individual outcome prediction, personalised treatment algorithms and new guidelines. Infect Disord Drug Targets 2011, 11:188-195.

32. Golubnitschaja O, Moenkemann H, Kim K, Mozaffari MS: DNA damage and expression of checkpoint genes p21(WAF1/CIP1) and 14-3-3 sigma in taurine-deficient cardiomyocytes. Biochem Pharmacol 2003, 66:511-517.

33. Bailey MM, Boohaker JG, Sawyer RD, Behling JE, Rasco JF, Jernigan JJ, Hood $\mathrm{RD}$, Vincent JB: Exposure of pregnant mice to chromium picolinate results in skeletal defects in their offspring. Birth Defects Res B Dev Reprod Toxicol 2006, 77:244-249.

34. Bagchi D, Stohs SJ, Downs BW, Bagchi M, Preuss HG: Cytotoxicity and oxidative mechanisms of different forms of chromium. Toxicology 2002, 180:5-22.

35. Mahmoud AA, Karam SH, Abdel-Wahhab MA: Chromium-picolinate induced ocular changes: protective role of ascorbic acid. Toxicology 2006, 226:143-151.

36. Coryell VH, Stearns DM: Molecular analysis of hprt mutations induced by chromium picolinate in CHO AA8 cells. Mutat Res 2006, 610:114-123.

37. Tan G-Y, Zheng S-S, Zhang M-H, Feng J-H, Xie P, Bi J-M: Study of oxidative damage in growing-finishing pigs with continuous excess dietary chromium picolinate intake. Biol Trace Elem Res 2008, 126:129-140.

38. Refaie FM, Esmat AY, Mohamed AF, Aboul Nour WH: Effect of chromium supplementation on the diabetes induced-oxidative stress in liver and brain of adult rats. Biometals 2009, 22:1075-1087. 
39. Jana M, Rajaram R, Rajaram A: Autoschizis of T-cells is induced by the nutritional supplement, Cr(III)picolinate. Toxicol In Vitro 2010, 24:586-596.

40. Stout MD, Nyska A, Collins BJ, Witt KL, Kissling GE, Malarkey DE, Hooth MJ: Chronic toxicity and carcinogenicity studies of chromium picolinate monohydrate administered in feed to F344/N rats and B6C3F1 mice for 2 years. Food Chem Toxicol 2009, 47:729-733.

41. Collins BJ, Stout MD, Levine KE, Kissling GE, Melnick RL, Fennell TR, Walden R, Abdo K, Pritchard JB, Fernando RA, Burka LT, Hooth MJ: Exposure to hexavalent chromium resulted in significantly higher tissue chromium burden compared with trivalent chromium following similar oral doses to male F344/N rats and female B6C3F1 mice. Toxicol Sci 2010, 118:368-379.

42. Lamson DW, Plaza SM: The safety and efficacy of high-dose chromium. Altern Med Rev 2002, 7:218-235.

43. Cerulli J, Grabe DW, Gauthier I, Malone M, McGoldrick MD: Chromium picolinate toxicity. Ann Pharmacother 1998, 32:428-431.

44. Wani S, Weskamp C, Marple J, Spry L: Acute tubular necrosis associated with chromium picolinate-containing dietary supplement. Ann Pharmacother 2006, 40:563-566.

45. Young PC, Turiansky GW, Bonner MW, Benson PM: Acute generalized exanthematous pustulosis induced by chromium picolinate. J Am Acad Dermatol 1999, 41:820-823.

46. Di Luigi L: Supplements and the endocrine system in athletes. Clin Sports Med 2008, 27:131-151.

47. Yeghiazaryan K, Cebioglu M, Golubnitschaja O: Global figures argue in favour of preventive measures and personalised treatment to optimise inadequate diabetes care. In New Strategies to Advance Pre/Diabetes Care: Integrative Approach by PPPM. Edited by Mozaffari M. Dordrecht: Springer; 2012. Golubnitschaja O (Series Editor): Advances in PPPM.

48. Gahan PB: Circulating nucleic acids in plasma and serum: roles in diagnosis and prognosis in diabetes and cancer. Infect Disord Drug Targets 2008, 8:100-108.

49. Golubnitschaja O: Clinical proteomics in application to predictive diagnostics and personalized treatment of diabetic patients. Curr Proteomics 2008, 5:35-44.

50. Golubnitschaja O, Costigliola V: Common origin but individual outcomes: time for new guidelines in personalized healthcare. Personalized Med 2010, 7:561-568

doi:10.1186/1878-5085-3-11

Cite this article as: Golubnitschaja and Yeghiazaryan: Opinion controversy to chromium picolinate therapy's safety and efficacy: ignoring 'anecdotes' of case reports or recognising individual risks and new guidelines urgency to introduce innovation by predictive diagnostics? The EPMA Journal 2012 3:11.

\section{Submit your next manuscript to BioMed Central and take full advantage of:}

- Convenient online submission

- Thorough peer review

- No space constraints or color figure charges

- Immediate publication on acceptance

- Inclusion in PubMed, CAS, Scopus and Google Scholar

- Research which is freely available for redistribution 